\title{
O Estudo Sobre de Drogas Lícitas e Ilícitas com Alunos do Ensino Médio em uma Escola Pública no Município de Humaitá-AM
}

\section{The Study on Legal and Illicit Drugs with High School Students in a Public School in the City of Humaitá-AM}

Doraci Brito de Souza ${ }^{\mathrm{a}}$; Pedro Henrique da Silva de Aguiara; Naelha Ramos de Carvalho ${ }^{\mathrm{a}}$; Viviane Guedes de Oliveira ${ }^{\mathrm{a}}$; Jorge Almeida de Menezes ${ }^{\mathrm{a}}$; Felipe Sant' Anna Cavalcante ${ }^{\mathrm{b}}$; Renato Abreu Lima ${ }^{\mathrm{a}}$

\begin{abstract}
aUniversidade Federal do Amazonas, Instituto de Educação, Agricultura e Ambiente, Curso Ciências: Biologia e Química. AM, Brasil. ${ }^{b}$ Universidade Federal do Amazonas, Programa de Pós-Graduação Stricto Sensu em Ciências do Ambiente e Sustentabilidade na Amazônia. AM, Brasil. *E-mail: renatoal@ufam.edu.br
\end{abstract}

\begin{abstract}
Resumo
O ambiente escolar é um promissor de conhecimentos, vivências e experiências, em que os estudantes são capazes de socializar com o todo o corpo escolar, além de adquirir um olhar e conhecimento crítico. Dessa forma, o presente artigo foi realizado no Centro de Educação em Tempo Integral (CETI) em Humaitá - AM. Buscou-se, através da sua realização, expor aos estudantes do Ensino Médio sobre a prevenção do uso drogas na escola, em que os mesmos puderam compreender e entender melhor sobre os efeitos biológicos e químicos no organismo. O artigo está pautado na proposta educativa contra o uso das drogas, por meio de sensibilizar os estudantes, bem como a comunidade do entorno da escola, utilizando ferramentas pedagógicas durante a sua execução. Por meio da sua realização se pôde observar que a curiosidade natural dos estudantes é um dos fatores de maior influência na experimentação de álcool e outras drogas. Essa curiosidade o faz buscar novas sensações e o efeito das drogas vai ao encontro disto, proporcionando prazer momentâneo. Diante dos fatos observados nas atividades, verificou-se que os alunos mostraram interesse pelas atividades realizadas, notando que os mesmos estavam concentrados na explicação do conteúdo ministrado.

Palavras-chave: Aprendizagem. Adolescência. Sociedade.
\end{abstract}

\begin{abstract}
The school environment is a promising place for knowledge, experiences and living, where students are able to socialize with the entire school body in addition to acquiring a critical look and knowledge. This article was carried out at the Full Time Education Center (CETI) in Humaitá - AM. Through its realization, it was sought to expose high school students about the drug use prevention at school, where they could better understand the biological and chemical effects on the body. The article is based on the educational proposal against the use of drugs by sensitizing students as well as the community around the school using pedagogical tools during their execution. Through its realization, it was observed that the students' natural curiosity is one of the factors of greatest influence in the experimentation of alcohol and other drugs. This curiosity makes him or her search for new sensations and the effect of drugs goes against this, providing momentary pleasure. In view of the facts observed in the activities, it was found that the students showed a good interest in the activities carried out, realizing that they were quite concentrated in explaining the content taught.
\end{abstract}

Keywords: Learning. Adolescence. Society.

\section{Introdução}

A história da produção e do uso de drogas faz parte da própria história da humanidade. Nas últimas décadas, porém, em função de sua elevada frequência, transformou-se em problema mundial de saúde pública, despertando o interesse de pesquisadores (TAVARES; BÉRIA; LIMA, 2004).

As primeiras experiências com drogas costumam ocorrer, frequentemente, na adolescência. Segundo De AlmeidaFilho (2007, p.2), o período da adolescência abrange uma determinada cronologia da vida, caracterizado por um processo de mudanças importantes. Nessa fase, o indivíduo é particularmente vulnerável do ponto de vista psicológico e social (SOLDERA, 2004). A adolescência constitui um período crucial no ciclo vital para o início do uso de drogas, seja como mera experimentação, seja como consumo ocasional, indevido ou abusivo (SCHENKER; MINAYO,
2005).

Partindo disto, a relação familiar que os adolescentes possuem se torna um dos principais vínculos que os levam a ter ou não contato com as drogas, sejam essas quais forem. $\mathrm{O}$ uso de drogas é uma problemática que cresce a cada dia e o que se percebe, na grande maioria das vezes, é o despreparo da sociedade para enfrentar essa situação. É na escola que a maioria dos jovens tem seu primeiro contato com as drogas,

No Brasil, a única pesquisa sistemática de abrangência nacional sobre uso de drogas na idade escolar e alguns fatores de risco é realizada pelo Centro Brasileiro de Informações sobre Drogas Psicotrópicas (Cebrid) há aproximadamente 15 anos (SOLDERA, 2004).

O uso abusivo de drogas pode provocar complicações crônicas e agudas como, por exemplo: intoxicação ou overdoses, com alterações duradouras ou até irreversíveis. Outros riscos também são considerados ao se tratar de 
adolescentes, pois todas as substâncias psicoativas, quando usadas de forma abusiva, aumentam o risco de acidentes e de violência por reduzirem os cuidados de autopreservação, já vulneráveis entre os adolescentes (DE ALMEIDA-FILHO, 2007).

Partindo do que foi relatado até aqui, é de grande importância prevenir o uso de drogas pelos adolescentes. Alguns autores como Büchele; Coelho; Lindner (2009, p.2) citam a importância da prevenção do uso de drogas pelos adolescentes.

A cada dia surgem novas drogas e com essas vários problemas sociais como a violência, a criminalidade, a prostituição e a disseminação de doenças, a evasão escolar e muitos outros. O uso de drogas é uma problemática que cresce a cada dia e o que se percebe, na grande maioria das vezes, é o despreparo da sociedade para enfrentar essa situação. É na escola que a maioria dos jovens tem seu primeiro contato com as drogas (ALMEIDA et al., 2019).

Em sua pesquisa, Moreira; Vóvio; De Micheli (2015, p.1) indicam a necessidade da construção e efetivação de trabalhos preventivos e de promoção de saúde, com vistas a reduzir os danos causados pelo consumo abusivo de álcool e outras drogas. E a escola tem sido considerada um espaço privilegiado para essas ações. Portanto, a família e a escola têm papel muito importante na prevenção do uso de drogas pelo adolescente estudante (BRUSAMARELLO et al., 2010).

O ambiente escolar é um promissor de conhecimentos, de vivências e de experiências, em que os estudantes são capazes de socializar com todo o corpo escolar, além de adquirir um olhar e conhecimento crítico. De acordo com os avanços dentro da sociedade, algumas questões devem ser debatidas em todo corpo estudantil, para que promova a saúde e o bemestar, advertindo sobre os perigos do uso das drogas, a frente de tal discussão e preocupação elaborou-se o "projeto de intervenção ao uso indevido de drogas lícitas e ilícitas com alunos do ensino médio em uma escola pública de tempo integral no município de Humaitá-AM", para que este venha ser um suporte auxiliar de prevenção redução aos perigos na saúde e vida dos educandos.

$\mathrm{O}$ artigo está pautado na proposta educativa contra o uso das drogas, sugerindo sensibilizar não somente os educandos, como também a comunidade de entorno da escola. Uma vez que nos últimos anos vêm ocorrendo mudanças na sociedade, e a escola tem uma importante função de inclusão diretamente de temas sociais, que ajudem no desenvolvimento dos jovens e adolescentes.

Sabe-se que um dos maiores desafios dos educadores é se adequar à maneira como os alunos pensam, tendo em vista o crescimento assustador do uso de drogas em torno da comunidade escolar. A escola deve criar uma estratégia para incluir a sociedade nesses problemas coletivos relacionados às drogas, fazendo com que essas dificuldades sejam esclarecidas sendo satisfatória e contextualizada através de apresentações.
Pensando em uma inclusão social em princípios humanistas, de respeito ao próximo se acredita que o "projeto intervenção ao uso indevido de drogas lícitas e ilícitas com alunos do Ensino Médio em uma escola pública de tempo integral no município de Humaitá-AM", irá colaborar com o fortalecimento em questões relacionadas ao uso de drogas, buscando a hospitalidade e não a rejeição do usuário e dos familiares.

Assim, realizar projetos de intervenção se torna um trabalho eficaz para toda a escola, oferecendo aos alunos uma compreensão do mundo das drogas, pois a vivência com as relações sociais possibilita a construção, a organização e a socialização do conhecimento, com o objetivo de sensibilizar os estudantes sobre a prevenção e o combate ao uso de drogas.

A realização deste artigo teve como objetivo sensibilizar os alunos para essa problemática social que atinge toda a sociedade, executado por um processo coletivo, vinculando a uma ação metodológica ligada aos estudantes do Centro de Educação de Tempo Integral Tarcila Prado de Negreiro Mendes localizada no município de Humaitá - AM que oferece o Ensino Médio (1 ${ }^{\mathrm{a}}, 2^{\mathrm{a}}$ e $3^{\mathrm{a}}$ séries do Ensino Médio), em especial, tem um ambiente privilegiado para a reflexão e formação de valores éticos e morais, e junto com os pais tem um papel fundamental na prevenção ao uso de drogas.

\section{Material e Métodos}

O presente trabalho foi realizado em novembro de 2019 pelos bolsistas do Programa Institucional de Bolsa de Iniciação à Docência (PIBID), da área de Biologia e Química, no Centro de Educação de Tempo Integral Tarcila Prado de Negreiro Mendes (CETI), no município de Humaitá-AM. Este trabalho tem caráter descritivo, o método utilizado foi uma abordagem qualitativa e relato de experiência. O público-alvo foram os alunos da $1^{\mathrm{a}}, 2^{\mathrm{a}}$ e $3^{\mathrm{a}}$ séries do Ensino Médio, sendo sete turmas da $1^{\mathrm{a}}$ série, oito turmas da $2^{\mathrm{a}}$ série e cinco turmas da $3^{\text {a }}$ série, com a finalidade de sensibilizar o uso indevido de drogas lícitas e ilícitas.

Para a aplicação deste trabalho houve encontro discursivo com os professores, coordenador e supervisor do PIBID para as escolhas das oficinas e divisão dos grupos. Em seguida, foram divididos cinco grupos de quatro bolsistas para a escolha dos temas abordados e apresentação das oficinas. Com relação aos pais e alunos, foram impressos e enviados panfletos informativos, alertando aos pais sobre o evento que iria ocorrer.

O trabalho teve início com apresentação de palestra utilizando recursos multimídias, em seguida oficinas educativas abordando o uso indevido de drogas lícitas e ilícitas na adolescência. Em diferentes salas de aulas, foram abordados os seguintes temas para apresentação: teoria sobre a química das drogas com apresentação da parte química através de cartazes e estruturas química tridimensional, juntamente com a participação dos bolsistas de Biologia, apresentando 
os efeitos biológicos e as principais partes afetadas do corpo humano ao uso abusivo de drogas, com apresentação de cartazes e maquetes.

Além disso, foram utilizados depoimentos gravados de ex-usuários de drogas, sendo dois pertencentes à comunidade escolar, que se disponibilizaram a participar do evento, com o consentimento dos mesmos foram apresentado aos alunos e professores presentes, a oficina de exposição de fotos: de famosos "artistas" e anônimos foram retiradas do Google Imagens para confecção de cartazes para a tal exposição para demonstração dos danos que as drogas causam na aparência de quem é usuário, mostrando antes e depois, demonstrando a realidade em que muitos jovens e adultos enfrentam sendo dependente químico, e exposição de documentário: Cracolândia - O Retrato do Caos: documentário dá voz aos usuários de crack, encontrado em https://www.youtube.com/ watch? $\mathrm{v}=$ dfsO16BA9zI.

Ao final de cada oficina foram distribuídos panfletos para melhorar a interpretação dos conteúdos ministrados, por meio das observações diretas no desempenho dos participantes durante as apresentações. Afinal, uma intervenção preventiva como parte de um sistema visa fortalecer os fatores de proteção com intuito de atribuir autonomia e responsabilidade aos jovens, possibilitando-lhes fazerem escolhas conscientes quanto ao uso indevido de drogas por meio da ponderação crítica sobre os efeitos e consequências do uso, diluindo assim os fatores de risco como normas e atitudes sociais favoráveis a experimentação (RONZANI, 2009).

\section{Resultados e Discussão}

Com base nas análises durante a aplicação das atividades realizadas na escola CETI, com os alunos pertencentes às três séries do Ensino Médio, sendo sete salas de $1^{\mathrm{a}}$ série, oito salas da $2^{\mathrm{a}}$ série e cinco salas da $3^{\mathrm{a}}$ série do centro educacional de tempo integral, participaram da palestra 546 alunos, com idade de 15 a 18 anos, sendo $57 \%$ meninos e $43 \%$ sendo meninas.

Pôde-se observar, ao longo do evento, que os alunos estiveram atentos e interessados aos relatos de experiência dos palestrantes, sobre sua história de vida, quando o mesmo era usuário de drogas, notando-se a curiosidade de questionar e interagir. Sabe-se que, na atualidade, muitos são os desafios impostos na área educacional e, consequentemente, para a área familiar, no que diz respeito à formação e a educação dos adolescentes (ROSAL; BRAGUINI, 2016).

Nas temáticas abordadas foram enfatizados aspectos educacionais relacionados ao tema, sempre contextualizando o tema com os familiares, com a sociedade, de forma que todos pudessem ser ativos neste ato de educar, indo ao encontro de estudo de Costa (1997), que trata a respeito de educação não ser apenas ensinar, mas sim mostrar aos alunos os riscos que as drogas causam perante a sociedade. Dessa forma, entendese que quando se fala em drogas, do ponto de vista legal, fazse referência às drogas lícitas e ilícitas (BRASIL, 2014).

Para a Organização Mundial de Saúde (OMS), drogas lícitas são aquelas que podem ser livremente comercializadas. Algumas estão submetidas a certas restrições. Por exemplo, bebidas alcoólicas e tabaco não podem ser comercializados por crianças e adolescentes. No caso de medicamentos, alguns só podem ser adquiridos por meio de prescrição médica especial. Enquanto as drogas ilícitas são aquelas proibidas por lei (BRASIL, 2014).

Após o término da palestra, os alunos foram liberados para participar das atividades nas salas de aula, sendo 20 alunos por sala com duração de 10 minutos de apresentação, na oficina sobre a parte biológica e química das drogas, foram apresentados os efeitos biológicos no corpo humano e as estruturas químicas das drogas, apresentando plantas que são consideradas drogas, mesmo sendo plantas do cotidiano através de desenhos ilustrativos, tais como: maconha, tabaco e café que, por sua vez, suas composições químicas podem tornar as pessoas dependentes, se usados de modo abusivo pode se levar a dependência e estes são meios em que os jovens não têm esses conhecimentos, logo de maneira didática se pode levar esse tal conhecimento.

Dessa forma, a abordagem teórica se fez necessária, porque leva em consideração pontos como coerência, conceitos, disposição dos conteúdos seguindo o princípio da progressão do conhecimento, que é a distribuição dos conteúdos orientando o desenvolvimento de estruturas de compreensão em escala crescente de complexidade em função do amadurecimento e da vivência do aluno (CAVALCANTE et al., 2016).

Para Arroyo (2011), a escola deve criar condições para que haja a sociabilidade de modo que os sujeitos sejam capazes de conviver, pois o aprendizado do mundo e da cultura passa por esta socialização.

$\mathrm{Na}$ oficina biológica, os tipos de drogas mais conhecidas foram apresentados nas exposições didáticas aos alunos, sendo o álcool, tabaco, maconha e cafeína, sendo que muitos acreditavam que a cafeína não era considerada como droga lícita, logo foi levada esse saber para aqueles que acreditavam que o café não causava nenhuma dependência, substâncias essas que são, frequentemente, usadas normalmente. Para Canavez; Alves; Canavez (2010), os fatores de risco que mais se destacam no momento em que o adolescente decide buscar o "mundo das drogas" estão ligados à mudança no afeto de seus familiares à vitimização por violência doméstica.

A organização das oficinas foi de suma importância, pois permitiu a realização de ações e atividades voltadas para cada grupo em específico, e envolveu a participação de todos, em prol do mesmo objetivo que é a participação nas ações realizadas na escola, a transformação da realidade, a formação de cidadãos atuantes e conscientes, principalmente, no que se refere ao uso de drogas.

$\mathrm{Na}$ parte química das drogas se apresentaram para os alunos as estruturas químicas das drogas, uma vez tudo que cerca a química está presente, sendo que quando usada indevidamente torna o indivíduo dependente, nessa oficina foi 
apresentado: a estrutura da nicotina, êxtase, cafeína, cocaína, maconha, álcool e pedra, são substâncias químicas que tornam os indivíduos dependentes e o desenvolvimento desta oficina resultou na participação efetiva dos alunos com interação e troca de informações através de seus conhecimentos sobre o tema abordado.

De acordo com Reis (2011), todo conhecimento que é adquirido na escola deve contribuir para que o educando transforme sua realidade individual e propicie a construção de novas realidades sociais. Libâneo (2010) cita que a pedagogia é um campo muito amplo dentro da educação, tem um grande conhecimento sobre a problemática educativa tanto em sua totalidade como em sua historicidade e, também, é a diretriz orientadora da ação educativa.

Além de ser uma estratégia motivadora para a assimilação dos conteúdos, sensibiliza a comunidade e conscientiza os adolescentes sobre essa problemática, permitindo a parceria entre escola e segurança pública, quando policiais podem ir à escola realizar palestras (SILVA, 2014).

Com a participação dos professores de Química e Biologia houve a oportunidade de levar os conhecimentos da realidade que muitos jovens enfrentam, por questão familiar ou por influência de amigos e acabam caindo no mundo das drogas, mesmo que sejam drogas lícitas, assim se faz necessário orientar e prevenir um ponto que se torna constante na sociedade.

Além disso, a família também deve fazer parte deste atendimento, dado o significado do contexto familiar nessas situações. Esta será atuante na responsabilização do adolescente perante seu tratamento, e ainda necessitará de apoio para lidar de forma compreensível com a situação (CANAVEZ; ALVES; CANAVEZ, 2010).

A instituição familiar é considerada um dos elos mais fortes dessa cadeia multifacetada que pode levar ao uso abusivo de álcool e drogas, além de também atuar como importante fator de proteção. Isto se explica pelo fato de que os diferentes comportamentos sociais, entre esses o consumo de substâncias psicoativas, que são aprendidos, predominantemente, a partir das interações estabelecidas entre o jovem e suas fontes primárias de socialização, que no Ocidente são a família, a escola e o grupo de amigos (DE PAIVA; RONZANI, 2009).

De acordo com Almeida; Soares (2010), apenas escolher e definir quais serão os conteúdos aplicados não é o suficiente, o aluno precisa se apropriar de um conhecimento que seja significativo para ele. Portanto, levar ao aluno temas que estão relacionados ao seu cotidiano é fundamental para que ele possa conhecer os riscos e as propriedades que a química das drogas causa.

Na oficina da parte social, três professores de Sociologia participaram dessa exposição que atuaram as orientações sociais para os alunos, mostrando que a vida social de uma pessoa depende do que ela é mediante a realidade de como se encontra seu estado físico e mental, evitando a discriminação e a exclusão, pois nem todas as pessoas aceitam um dependente na sociedade, isso mostra que esses são os principais fatores que um dependente pode vir a sofrer.

Utilizando-se de fotografias e cartazes mostrando o antes e o depois da dependência, foram relatados aos alunos os danos causados em sua vida social e familiar, com isso houve a oportunidade de mostrar a eles quando o indivíduo se torna um dependente químico sua vida social pode ter várias perdas, tanto na família como na sociedade. Diante do que foram expostos nesta oficina, os alunos tiveram influência mútua nesta prática no momento da exposição, uma contribuição satisfatória para um melhor entendimento sobre os danos causados por uso de drogas.

Em torno de 30\% dos alunos, que participaram deste trabalho, relataram que possuem dependentes químicos na família, e que as oficinas e relatos foram fundamentais para repassarem essa informação aos demais familiares, por levar a vida em risco e usadas em exceção leva o indivíduo ao transtorno mental, e sim colocando a saúde e a sociedade em risco. Segundo Rozin; Zagonel (2012) e Mosqueda-Diaz e Ferriani (2011) que afirmam que o consumo de álcool e drogas ilícitas, por parte de algum membro da família, induz e facilita o uso de álcool e tabaco por adolescentes. Malbergier et al. (2012) salientam que diversos fatores relacionados ao sistema familiar têm sido associados ao risco para o uso de substâncias entre os adolescentes, entre esses, a avaliação negativa da relação familiar, a falta de suporte/monitoramento e o uso de drogas por familiares.

Almeida et al. (2019) ao compreender a relação dos estudantes do Ensino Médio de uma escola pública no interior do Amazonas com as drogas lícitas e ilícitas, verificouse que a primeira experiência com as drogas, da maioria dos estudantes, foi na faixa etária entre 15 a 17 anos. Os estudantes de menor faixa usam mais drogas ilícitas e os de maior faixa etária usam mais drogas lícitas. Entre as drogas lícitas e ilícitas mais consumidas pelos alunos se encontram o álcool, a maconha, o tabaco, a cocaína e o crack. Entre os fatores que influenciaram os estudantes na experimentação ou uso frequente dessas se destacam a presença de usuários na família e curiosidades para experimentar.

As fotografias expostas relataram o antes e depois da dependência, nessa apresentação os alunos participaram apenas por meio de observação, mediante da realidade que os dependentes sofrem, o que era belo com o tempo começam a sofrer as consequências, e com isso, sensibilizá-los através dessa realidade, que o uso de drogas pode ter seus efeitos de prazer, mas também seus danos tanto no individual como coletivo.

Além de mostrar a realidade dos efeitos colaterais que as drogas causam tanto as lícitas quanto as ilícitas, os alunos puderam observar os danos causados pelas drogas não somente no corpo do usuário, mas também na vida dos mesmos. Diante das exposições, foi repassado aos alunos, o quão difícil foi para os ex-usuários de drogas que compartilharam com os alunos através de seus depoimentos gravados, o quão difícil 
foi para eles recuperarem uma parte de sua vida que foi deixada de ser vivida,

No ato do depoimento, que duraram cerca de 20 minutos, a cada 20 minutos, os professores responsáveis entravam com 20 alunos por vez a cada troca no final da apresentação houve entrega de panfleto, com instruções e alerta sobre o uso de drogas.

Logo se faz necessário que a escola esteja pronta a programar relações interpessoais entre educador e aluno, que estejam preparados a lidar com situações do tipo, uma vez que os jovens subsistam mais vulneráveis e estejam expostos em situações preocupantes, então necessitam ser orientados tanto no ambiente escola como em casa, diante da realidade possam estar preparados para encarar a realidade em que vivemos nos tempos atuais. As drogas se constituem, sem dúvida, uma grande ameaça à humanidade e à manutenção das estruturas e valores familiares, políticos, econômicos, sociais e culturais. Suas consequências avançam por todos os espaços (ROSAL; BRAGUIN, 2016).

Para Pinotti (2007, p.30) “a prevenção de drogas nas escolas acontece com atividades preventivas e cotidianas na sala de aula". Não adianta a escola determinar no calendário escolar uma palestra com o tema "DROGAS" anualmente. Além disso, o contato com a escola por meio do PIBID amplia a participação do futuro docente da Educação Básica em experiências próprias do processo de ensino e aprendizagem, a fim de promover uma formação que atenda às exigências de uma sociedade em constante transformação (SILVA; MARTINES; LIMA, 2019).

\section{Conclusão}

Notou-se que os alunos necessitam auferir mais direções que apontam terem mais conhecimentos diante dos fatos que as drogas possam causar e levar a eles os grandes problemas que a dependência causa, prevenindo de grandes danos que possam afetar futuramente tanto a saúde como conflitos familiares, através da ação deste projeto, acredita-se que se conseguiu despertar nos alunos os riscos que as drogas causam e, com isso, mostrar os perigos que são enfrentados na sociedade, com base nas observações houve bons resultados, pois os alunos participaram de todas as atividades realizadas durante a aplicação do projeto, participando de forma ativa dos processos de apresentação.

Nesse contexto, a participação do PIBID é sempre de intervir nas dificuldades que os alunos enfrentam na escola, por serem alunos de ensino de tempo integral da rede básica, muitas vezes se sentem presos no ambiente, pois é o lugar que passam mais tempo de suas vidas no decorrer de sua formação escolar, no entanto o PIBID proporciona temáticas de intervenção, inovando nos meios de ensino e interação em sala de aula. Desses conjuntos de bolsistas de iniciação à docência houve o privilégio de agir em cima de uma problemática que muitas escolas enfrentam que são as drogas na adolescência.
Mesmo que se esteja em outra jornada, a expectativa deste trabalho é fazer com que esse conhecimento esteja sempre presente na vida de cada dos alunos que participaram de forma direta e indireta e que a escola continue levando esse conhecimento, essa experiência a novos alunos que tendem a chegar nessa escola e que os demais professores estejam sempre orientando ao uso indevido das drogas, uma vez que esses jovens serão os próximos professores, gestores ou em outras áreas em outras áreas de conhecimento, para isso devem estar preparados para a realidade perante a sociedade e as dificuldades, que possam enfrentar no decorrer de suas vidas.

\section{Agradecimentos}

A gestora do Centro de Educação Tarcila Prado de Negreiro Mendes (CETI), aos professores, aos alunos à Capes por nos proporcionar esta oportunidade de compartilhar estes conhecimentos.

\section{Referências}

ALMEIDA, C.M.; SOARES, K.C.D. Pedagogo Escolar: as funções supervisora e orientadora. Curitiba: Ibpex, 2010.

ALMEIDA, W.A. et al. Drogas lícitas e ilícitas: o cenário em uma escola pública em Benjamin Constant-AM. Rev. Ensino Ciênc. Hum., v.5, n.2, p.724-753, 2019.

ARROYO, M.G. Imagens quebradas: trajetórias e tempos de alunos e mestres. Petrópolis: Vozes, 2011.

BRASIL. Secretaria Nacional de Políticas sobre Drogas. Curso de Prevenção do uso de drogas para educadores de escolas públicas. Brasília: Ministério da Justiça, 2014.

BRUSAMARELLO, T. et al. Papel da família e da escola na prevenção do uso de drogas pelo adolescente estudante. Ciênc. Cuidado Saúde, v.9, n.4, p.766-773, 2010. doi: https://doi. org/10.4025/cienccuidsaude.v9i4.13828.

BÜCHELE, F.; COELHO, E.B.S.; LINDNER, S.R. A promoção da saúde enquanto estratégia de prevenção ao uso das drogas. Ciênc. Saúde Coletiva, v.14, p.267-273, 2009. doi: https://doi. org/10.1590/S1413-81232009000100033.

CAVALCANTE, F.S. et al. O ensino-aprendizagem de pteridófitas por meio da aula prática em uma escola pública no município de Porto Velho-RO. South Am. J. Basic Educ. Technical Technol., v.3. n.2, p.10-15, 2016.

CANAVEZ, F.M.; ALVES, R.A.; CANAVEZ, S.L. Fatores predisponentes para o uso precoce de drogas por adolescentes. Cad. UniFOA, v.5, n.14, p.57-63, 2010. doi: https://doi. org/10.47385/1021rt.

COSTA, A.C.G. Pedagogia da presença: da solidão ao encontro. Belo Horizonte: Modus Faciendi, 1997.

DA ROSAL, S.P.; BRAGUINI, W.L. Drogas e ambiente escolar: desafios da educação. Os desafios da escola pública paraense na perspectiva do professor PDE. Curitiba: Governo do Estado do Paraná, 2006.

DE ALMEIDA FILHO, A.J. et al. O adolescente e as drogas: consequências para a saúde. Esc. Anna Nery Rev. Enferm., v.11, n.4, p.605-610, 2007. doi: https://doi.org/10.1590/S141481452007000400008 .

DE PAIVA, F.S.; RONZANI, T.M. Estilos parentais e consumo 
de drogas entre adolescentes: revisão sistemática. Psicol. Estudo, v.14, n.1, p.177-183, 2009.

MALBERGIER, A.; CARDOSO, L.R.D.; AMARAL, R.A. Uso de substâncias na adolescência e problemas familiares. Cad. Saúde Pública, v.28, n.4, p.678-688, 2012. doi: https://doi. org/10.1590/S0102-311X2012000400007.

MOREIRA, A.; VÓVIO, C.L.; DE MICHELI, D. Prevenção ao consumo abusivo de drogas na escola: desafios e possibilidades para a atuação do educador. Educ. Pesq., v.41, n.1, p.119-135, 2015. doi: https://doi.org/10.1590/S1517-97022015011670.

MOSQUEDA-DIAZ, A.; FERRIANI, M.G.C. Factores protectores y de riesgo familiar relacionados al fenómeno de drogas, presentes em familias de adolescentes tempranos de Valparaíso, Chile. Rev. Latinoam. Enferm., v.19, n.1, p.789-795, 2011. doi: https://doi.org/10.1590/S0104-11692011000700017.

REIS, T. Educação e cidadania: a batalha de uma Educação comprometida. Rio de Janeiro: Wak, 2011.

RONZANI, T.M. Prevenção ao uso de álcool e outras drogas. São João Del Rei: NEAD/UFSJ, 2009.
ROZIN, L.;ZAGONEL, I.P.S. Fatores de risco para dependência de álcool em adolescentes. Acta Paul. Enferm., v.25, n.2, p.314-318, 2012. doi: https://doi.org/10.1590/S0103-21002012000200025.

SILVA, F.S.P.; MARTINES, E.A.L.M.; LIMA, R.A. Iniciação à Docência em Escola da Rede Pública em Porto Velho-RO. Rev. Multidisc. Educ., v.6, n.14, p.69-82, 2019. doi: https://doi. org/10.26568/2359-2087.2019.2835.

SCHENKER, M.; MINAYO, M.C.S. Fatores de risco e de proteção para o uso de drogas na adolescência. Ciênc. Saúde Coletiva, v.10, n.3, p.707-717, 2005. doi: https://doi.org/10.1590/ S1413-81232005000300027.

SOLDERA, M. et al. Uso de drogas psicotrópicas por estudantes: prevalência e fatores sociais associados. Rev. Saúde Pública, v.38, n.2, p.277-283, 2004. doi: https://doi.org/10.1590/S003489102004000200018 .

TAVARES, B.F.; BÉRIA, J.U.; LIMA, M.S. Fatores associados ao uso de drogas entre adolescentes escolares. Rev. Saúde Pública, v.38, n.6, p.787-796, 2004. doi: https://doi.org/10.1590/S003489102004000600006 . 